\title{
Preface
}

\section{Cyanobacteria and cyanotoxins: responses and detection}

\author{
LI Renhui (李仁辉) ${ }^{1,}{ }^{*}$, SONG Lirong (宋立荣) ${ }^{2}$, Philip T. ORR ${ }^{3}$

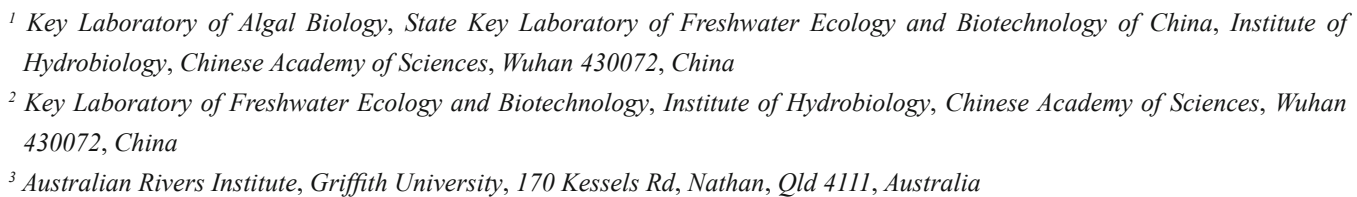

Received Jul. 1, 2018; accepted for publication Jul. 8, 2018

(C) Chinese Society for Oceanology and Limnology, Science Press and Springer-Verlag GmbH Germany, part of Springer Nature 2018

The $10^{\text {th }}$ International Conference on toxic cyanobacteria (ICTC-10) was successfully held during 23-28 Oct. 2016. We were so glad to see much progress made on toxic cyanobacteria and cyanotoxins during past years, and the ICTC does provide a global forum for a wide-ranging communication and discussion of key issues related to cyanobacterial blooms and cyanotoxins.

This special issue "Cyanobacteria and cyanotoxins: responses and detection" in Journal of Oceanology and Limnology includes a collection of twelve papers focus on different topics and approaches on diversity, detection and physiological responses of cyanobacterial blooms and cyanotoxins. Seven papers include physiological responses of toxic cyanbacteria to environmental factors. As presented in the keynote speak at ICTC-10, Burford et al. (2018) provided the recent progress on studies about physiological responses to nutrients by toxic Cylindrospermopsis raciborskii, a widespread species with a high level of flexibility with respect to light and nutrients, and they summarized that an important component of this flexibility appears to be the result of within-population strain variability in responses to nutrients, as well as key physiological adaptations.

Peng et al. (2018) deal with the response of Microcystis aeruginosa to different nutrient ratios and changes in phosphorus chemistry, and their results demonstrated the effects of different phosphorus chemistries and $\mathrm{N}: \mathrm{P}$ ratios on the cyanobacterial growth, photosynthetic activity and cell physiology, which could be an effective tool for predicting cyanobacterial dominance or $\mathrm{N}$-deficiency in natural lakes.
Huang et al. (2018) investigated the effect of light availability on the specific density, size and sinking loss of Anabaena flos-aquae and Scenedesmus obliquus, and the results implied that the sinking loss rate of the two algal species was not always constant but should be considered as a variable response to the change of light availability.

Orr et al. (2018) reviewed the importance of assessing changes in cyanotoxin cell quotas $(Q)$ in response to external stressors, and they showed how first-order rate kinetics at the cellular level can be used to explain how environmental conditions drive changes in bloom toxicity at the ecological level. In summary, those stressors drive changes in bloom toxicity through the effect they have on the rates of cell division and growth of different strains with genetically different cyanotoxin cell quotas, and not through any stimulatory or trigger effect on the toxin production pathway itself.

Wang et al. (2018) provided an exceptional example for the study of regime shift during the last 50 years in Lake Dianchi (China), a plateau shallow lake. The shift, characterized as the dominance of submerged macrophyte into the dominance of phytoplankton (mostly cyanobacteria), has occurred since 1993, and they concluded that the threshold concentrations at which regime shift occurred were total nitrogen (TN) and phosphorus (TP) reaching $1.2 \mathrm{mg} / \mathrm{L}$ and $0.13 \mathrm{mg} / \mathrm{L}$, respectively.

Rozina et al. (2018) detected the effect of electrochemical oxidation on Microcystis aeruginosa

\footnotetext{
* Corresponding author: reli@ihb.ac.cn
} 
appling the combination of two sensors as a useful tool for in-vivo detection of induced stress, providing real-time information needed for the evaluation of the efficiency of the in-lake treatment and decision upon the necessity of its repetition. The resuts showed that the electrochemical treatment also resulted in a lower free microcystins concentration compared to control.

Dai et al. (2018) prepared powdered activated carbon (PAC) modified with $\mathrm{Fe}(\mathrm{III})$ as PAC-Fe(III) and utilized it for the fast and efficient removal of microcystins from water. PAC-Fe(III) exhibited superior microcystin-LR removal capacity and efficiency compared to the unmodified PAC. The MCLR removal efficiency of PAC-Fe(III) increased with decreasing $\mathrm{pH}$ within the $\mathrm{pH}$ range of 4.3 to 9.6 , and PAC-Fe(III) could be further reused, suggesting that $\mathrm{Fe}$ modified PAC is a promising material for the treatment of MC-contaminated waters.

Next, five papers in this special issue deal with the detection of bloom forming cyanobacteria and cyanotoxins in waters. Mckay at al. (2018) presented a toxic Planktothrix agardhii bloom detected in the Maumee River, the largest tributary to Lake Erie during nearly one week between May-June 2016, with highest MC-LR reaching over $22 \mu \mathrm{g} / \mathrm{L}$. This early onset, microcystin-producing bloom provided a rare opportunity to shed insights into environmental factors that promote bloom development and dominance by Planktothrix in lotic environments.

Han et al. (2018) reported spatial and temporal variations in cyanobacteria and microcystins in Aha Reservoir, Guizhou province, southwest China. As a representative of drinking water resource, this reservoir suffered from annual cyanobacterial blooms dominated by Microcystis sp., mixing with Aphanizomenon flos-aquae and Pseudanabaena limnetica, and Microcystin levels were between $0-3.0 \mu \mathrm{g} / \mathrm{L}$. The results of this study indicate that the reservoirs used for drinking waters in this region should be monitored regularly to minimize potential health risks to the human population.

Zuo et al. (2018) evaluated different $m c y$ genes for detecting the toxic to non-toxic Microcystis ratio in the field by multiplex qPCR since molecule biological detection for microcystin producing cyanobacteria has been largely performed, and they indicated that $m c y D$ was the most suitable $m c y$ gene for quantification in laboratory experiments compared to $m c y B$ which abundances were always higher. These results will help to choose $m c y$ regions for conducting real-time PCR to detect toxic cyanobacteria in waters.
Huo et al. (2018) who used high-throughput sequencing of $16 \mathrm{~S}$ rDNA to investigate the aquatic bacterial community structure along the water course from Yuqiao Reservoir to Haihe River in Tianjin, China during a bloom in 2016. They found distinct bacterial communities associated with Microcystis vs Synechococcus dominated waters respectively, and applying high throughput sequencing could offer a wide field of vision in analyzing microbial community structures.

Final paper in this collection written by Shen et al. (2018) who used the polyphasic approach to characterize a coccoid cyanobacterium Merismopedia tenuissima. This paper seemed not deal with the toxic cyanobacterial taxa, but the Merismopedia species are commonly found in aquatic environments with different trophic states, and some species were even found as the dominant species as a bloom state in the eutrophic water. Polyphasic characterization on the M. tenuissima strains brought some addition to the general view and basic knowledge for the classification and systematics of the genus Merismopedia, and further enhanced the monitoring capacity for unicellular non-Microcystis dominated blooms.

We thank Journal of Oceanology and Limnology editor Roger Z. YU for giving us the opportunity to edit this special issue and supervising the whole editorial process, and we also thank all reviewers that have thoroughly reviewed these manuscripts. We hope that this collection of papers will be of interest for a broad scientific audience and will provoke new ideas and new research programs from a wide range of water bodies.

\section{References}

Burford M A, Willis A, Chuang Ann, Man X, Orr P. 2018. Recent insights into physiological responses to nutrients by the cylindrospermopsin producing cyanobacterium, Cylindrospermopsis raciborskii. Journal of Oceanology and Limnology, 36(4): 1 032-1 039.

Dai G F, Gan N Q, Song L R, Fang S W, Peng N Y. 2018. Fast adsorption of microcystin-LR by $\mathrm{Fe}$ (III)-modified powdered activated carbon. Journal of Oceanology and Limnology, 36(4): 1 103-1 111.

Han M S, Li Q H, Chen H L, Xiao J, Jiang F. 2018. Spatial and temporal variations in cyanobacteria and microcystins in Aha Reservoir, Southwest China. Journal of Oceanology and Limnology, 36(4): 1 126-1 131.

Huang Y Y, Zhang H C, Gao R F, Huang X C, Yu X J, Chen X C. 2018. Influence of light availability on the specific density, size and sinking loss of Anabaena flos-aquae and Scenedesmus obliquus. Journal of Oceanology and Limnology, 36(4): 1 053-1 062. 
Huo D, Chen Y X, Liu P, Li Y M, Qiao Z Y, Li R H. 2018. Molecular detection of microbial communities associated with Microcystis vs Synechococcus dominated waters in Tianjin, China. Journal of Oceanology and Limnology, 36(4): 1 145-1 156.

McKay R M L, Tuttle T, REITZ L A, Bullerjahn G S, Cody W R, McDowell A J, Davis T W. 2018. Early onset of a microcystin-producing cyanobacterial bloom in an agriculturally-influenced Great Lakes tributary. Journal of Oceanology and Limnology, 36(4): 1 112-1 125.

Orr P T, Willis A, Burford M A. 2018. Application of first order rate kinetics to explain changes in bloom toxicity - the importance of understanding cell toxin quotas. Journal of Oceanology and Limnology, 36(4): 1 063-1 074.

Peng G T, Wilhelm S W, Lin S J, Wang X R. 2018. Response of Microcystis aeruginosa FACHB-905 to different nutrient ratios and changes in phosphorus chemistry. Journal of Oceanology and Limnology, 36(4): 1040 1052.

Rozina T, Eleršek T, Zupančič Justin M, Meglič A, Leštan D,
Sedmak B. 2018. The effects of electrochemical oxidation on in-vivo fluorescence and toxin content in Microcystis aeruginosa culture. Journal of Oceanology and Limnology, 36(4): 1 091-1 102.

Shen L Q, Ma S C, Cai F F, Yu G L, Li S C, Li R H. 2018. Polyphasic examination on Merismopedia tenuissima CHAB 7021 from Ganjiang River, China revealed the polyphyly of the genus Merismopedia (Cyanobacteria). Journal of Oceanology and Limnology, 36(4): $1157-$ 1165.

Wang Y C, Wang W B, Wang Z, Li G B, Liu Y D. 2018. Regime shift in Lake Dianchi (China) during the last 50 years. Journal of Oceanology and Limnology, 36(4): 1075 1090.

Zuo J, Chen L T, Shan K, Hu L L, Song L R, Gan N Q. 2018. Assessment of different $m c y$ genes for detecting the toxic to non-toxic Microcystis ratio in the field by multiplex Qpcr. Journal of Oceanology and Limnology, 36(4): 1 132-1 144. 